Vol. 2 No. 2 (2021), Halaman 131-136

ISSN 2774-6968
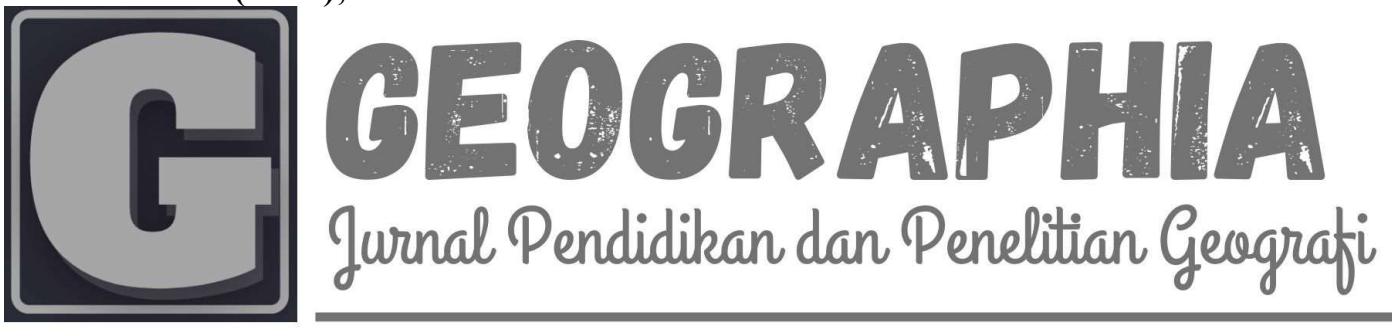

\title{
PENERAPAN MODEL PEMBELAJARAN BERBASIS MASALAH (PBL) PADA MATA PELAJARAN GEOGRAFI DI SMAN 1 LANGOWAN
}

\author{
Afriliandy Tumbelaka ${ }^{1}$, Xaverius Erick Lobja ${ }^{2}$, Ellen Eva Poli ${ }^{3}$ \\ ${ }^{1}$ Jurusan Pendidikan Geografi, Universitas Negeri Manado \\ Email: atumbelaka1999@gmail.com \\ ${ }^{2}$ Jurusan Pendidikan Geografi, Universitas Negeri Manado \\ Email: ericklobja@unima.ac.id \\ ${ }^{3}$ Jurusan Pendidikan Geografi, Universitas Negeri Manado \\ Email: ellenpoli@unima.ac.id
}

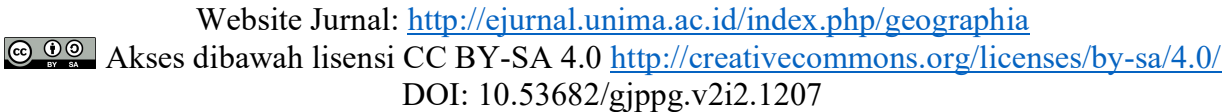

(Diterima: 11-05-2021; Direvisi: 24-10-2021; Disetujui: 10-11-2021)

\begin{abstract}
The background of the research is an effort to develop the quality and explore the potential of students. Teachers are strived to use the right learning model, namely problem-based learning models combined with online learning methods (learning from home) that have been decided by the Ministry of Education and Culture during the Covid-19 pandemic. The purpose of this study was to determine the application of problem-based learning models in improving student learning outcomes in geography subjects at SMAN 1 Langowan. The method used is a quasi-experimental design with a pretests-posttests control group design. The research variable with the independent variable is the problem-based learning model and the dependent variable is the learning outcome. The results showed that the problem-based learning model was effective and efficient to improve student learning outcomes. The comparison of learning outcomes shows the experimental class with 76.2 pretests and 87.7 posttests and the control class with 74.4 pretests and 81.8 posttests. It also encourages students to be more active and creative in overcoming the problems encountered in learning.
\end{abstract}

Keywords: Application, Geography, Learning, Model, Problem based.

\section{ABSTRAK}

Latar belakang dari penelitian adalah upaya mengembangkan kualitas dan menggali potensi siswa. Guru diupayakan menggunakan model pembelajaran yang tepat yaitu model pembelajaran berbasis masalah yang dipadukan dengan metode pembelajaran daring (belajar dari rumah) yang telah diputuskan oleh Kemendikbud selama masa pandemi Covid-19. Tujuan penelitian ini adalah untuk mengetahui penerapan model pembelajaran berbasis masalah dalam meningkatkan hasil belajar siswa pada mata pelajaran geografi di SMAN 1 Langowan. Metode yang digunakan adalah kuasi eksperimen dengan jenis disain pretests-posttests control group design. Variabel penelitian dengan variabel bebas adalah model pembelajaran berbasis masalah dan variabel terikat adalah hasil belajar. Hasil penelitian menunjukkan model pembelajaran berbasis masalah efektif dan efisien untuk meningkatkan hasil belajar siswa. Perbandingan hasil belajar menunjukkan kelas eksperimen dengan pretests 76,2 
dan posttests 87,7 dan kelas kontrol dengan pretes 74,4 dan posttests 81,8 . Selain itu juga mendorong siswa lebih aktif dan kreatif dalam mengatasi masalah-masalah yang dihadapi dalam pembelajaran.

Kata Kunci: Berbasis masalah, Geografi, Model, Pembelajaran, Penerapan.

\section{PENDAHULUAN}

Pendidikan

meningkatkan sumber daya manusia berkualitas. Manusia akan sulit mengembangkan kebudayaan dan akan terbelakang tanpa adanya pendidikan. Pendidikan pada saat menjadi isu penting ditengah disrupsi teknologi yang menuntut paradigma baru kepada guru dan siswa berkaitan dengan kurikulum, pembelajaran dan asesmen. Disisi lain bahwa proses pembelajaran merupakan inti dari pendidikan (Rasyid, 2018).

Keberhasilan hasil pembelajaran dapat dilihat dari sejauhmana pembelajaran dapat membawa perubahan dalam aspek pengetahuan, nilai, sikap dan kepribadian siswa. Ini sejalan dengan pendapat bahwa belajar merupakan proses perubahan tingkah laku hasil pengalaman bertinteraksi dengan lingkungan (Rosma, 2017). Perubahan tersebut ditampakkan pada bentuk kecapakan pengetahuan, sikap, kebiasaan, pemahaman, keterampilan, daya pikir dan kemampuan lainnya (Dimyati \& Mudjiono, 1999). Hal tersebut dapat diwujudkan dengan pembelajaran efektif dan efisien. Pelibatan siswa dalam proses pembelajaran diperlukan untuk meningkatkan kualitas dan potensi seorang siswa (Pese et al., 2012).

Ketercapaian dari proses pembelajaran ini identik dengan hasil belajar siswa. Hasil belajar didefinisikan sebagai kompetensi aspek kognitif, afektif, dan psikomotorik yang dicapai setelah proses pembelajaran (Rusman, 2011). Ketiga aspek tersebut diukur melalui evaluasi ketercapaian tujuan pembelajaran. Hasil belajar ini berkaitan dengan keberhasilan siswa untuk mencapai kemampuan tertentu. Oleh karena itu tiap kompetensi dasar (KD) materi pelajaran, ditetapkan kriteria ketuntasan minimal (Wahyuni et al., 2014).

Sebagai upaya mengembangkan kualitas dan menggali potensi siswa, guru diupayakan menggunakan model pembelajaran yang tepat. Selain itu, guru dituntut dapat melaksanakan kegiatan pembelajaran yang mengkonstruksi pemahaman (Rifani, 2013). Menurut Joice dan Weil (1973) menjelaskan model pembelajaran ini mempunyai pengertian pola perencanaan pembentukan kurikulum, bahan pembelajaran dan pembimbingan pembelajaran di kelas (Rusman, 2011).

Pembelajaran yang dapat dikembangkan untuk meningkatkan kualitas dan potensi siswa adalah model pembelajaran berbasis masalah yaitu pembelajaran yang mengupayakan penemuan solusi dalam diagnosa dengan membuat pertanyaan sesuai situasi yang ada (Sumartini, 2015). Kemampuan ini menekankan pada pembelajaran yang sistematis untuk menemukan sebuah solusi logis terhadap sebuah isu (Woa, 2018).

Pembelajaran berbasis masalah menuntut siswa belajar kooperatif dalam kelompok. Pembelajaran ini dilakukan dengan cara pemberian tugas dan guru yang dipantau secara daring atau mengunjungi langsung ke rumah siswa untuk memastikan kesiapan siswa untuk memulai pembelajaran. Kerangka berpikir mengenai proses pembelajaran jelaskan pada Gambar 1.

Berdasarkan uraian diatas, penelitian ini bertujuan untuk mengetahui penerapan model pembelajaran berbasis masalah dalam meningkatkan hasil belajar siswa pada mata pelajaran Geografi di SMAN 1 Langowan. Penerapan model pembelajaran berbasis masalah dilakukan dengan metode pembelajaran daring (belajar dari rumah) yang telah diputuskan oleh Kemendikbud selama masa pandemi Covid-19. Sumber atau media pembelajaran memanfaatkan media online berbentuk audio visual, dan presentasi multimedia. Kemajuan teknologi sangat berpengaruh tehadap interaksi yang mengalami perubahan. Dimana semula pembelajaran langsung dikelas, berubah dengan memanfaatkan jaringan internet (online learning) (Putri \& Muzakki, 2019; Widodo \& Mukminan, 2018).

\section{METODE PENELITIAN}

Metode yang digunakan adalah kuasi eksperimen dengan jenis disain pretestsposttests control group design. Variabel bebas penelitian adalah model pembelajaran berbasis masalah dan variabel terikat adalah hasil belajar. Kelas X IPS 1 sebagai kelas eksperimen 
(pembelajaran dengan model berbasis masalah secara daring) dan kelas X IPS 2 sebagai kelas kontrol (tidak diberikan model pembelajaran berbasis masalah secara daring) dengan lokasi penelitian di SMAN 1 Langowan.

Teknik pengumpulan data bersumber dari tes hasil belajar siswa dalam pembelajaran
Geografi. Dilakukan dengan mengirim materi dan tes hasil belajar melalui media Google Classroom dan WhatsApp Group. Tes hasil belajar dalam bentuk tes essai.

Teknik analisis data dilakukan pada hasil jawaban tes yang dikirimkan melalui Google

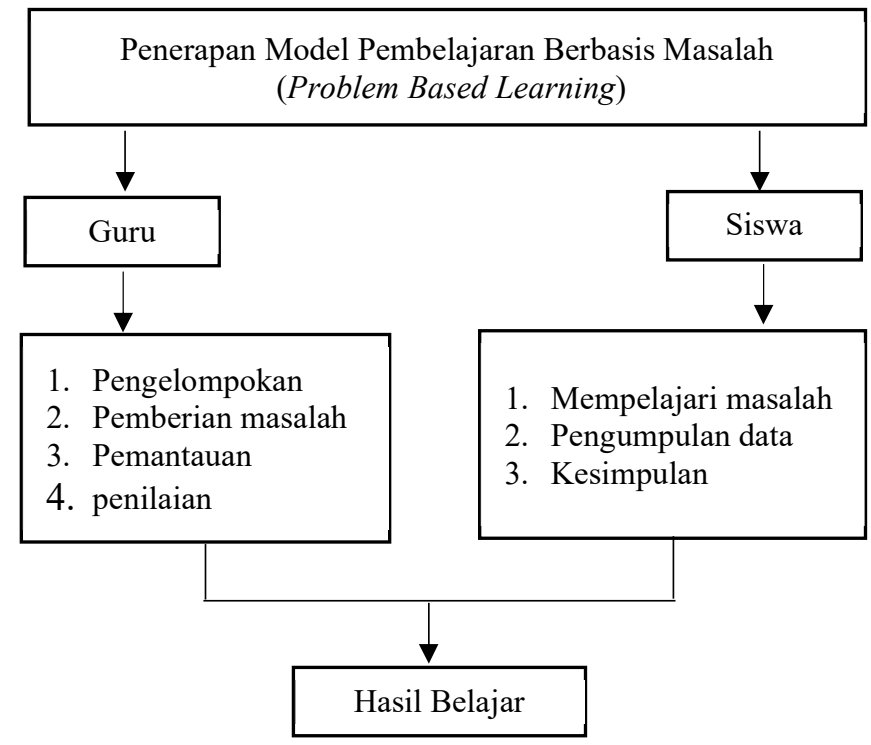

Gambar 1.

\section{Kerangka Berpikir Penelitian}

Classroom dan WhatsApp Group pada waktu yang sudah di ditentukan oleh guru.

Untuk menentukan signifikan perbedaan yang timbul sebagai akibat penerapan model pembelajaran, digunakan perhitungan rancangan penelitian kuasi eksperimen Pretests-Posttests Control Group Design yang dijelaskan pada rumus berikut.

$(\mathrm{T} 2 \mathrm{E}-\mathrm{T} 1 \mathrm{E})-(\mathrm{T} 2 \mathrm{C}-\mathrm{T} 1 \mathrm{C})$

Keterangan:

T1E : Pretests kelompok eksperimen

T2E : Posttests kelompok ekperimen

T1C : Pretests kelompok kontrol

T2C : Posttests kelompok kontrol

\section{HASIL PENELITIAN}

Hasil penelitian ini diperoleh dari 60 siswa yang terdapat pada dua kelas yakni 30 orang siswa X IPS 1 dan 30 siswa X IPS 2 SMA Negeri 1 Langowan. Data tersebut diperoleh dari hasil observasi langsung pada mata pelajaran Geografi dengan materi yang diajarkan adalah konsep, prinsip dan pendekatan Geografi. Metode yang digunakan adalah metode konvensional seperti guru hanya memberikan penjelasan materi secara singkat melalui WhatsApp Group dan mengirimkan tugas melalui Google Classroom untuk kelompok kelas X IPS 2 sebagai kelompok kontrol atau kelompok pembanding. Kelompok kelas X IPS 1 selaku kelompok eksperimen atau yang diberi perlakuan seperti diberikan langkah-langkah dalam pembelajaran berbasis masalah kemudian mengumpulkan tugas melalui WhatsApp Group dan Google Classroom.

Langkah-langkah model pembelajaran berbasis masalah secara daring dapat dijelaskan sebagai berikut; a) siswa diberi kasus permasalahan untuk diselesaikan dengan diskusi, b) siswa dibagi menjadi beberapa kelompok (dengan ketentuan antar rumah anggota kelompok berdekatan sebagai antisipasi jika diperlukan pertemuan diskusi langsung) untuk mendiskusikan permasalahan mencakup membuat pernyataan-pernyataan masalah dan membuat hipotesis-hipotesis, c) siswa kemudian mencari data dan informasi dari berbagai sumber, d) siswa melakukan diskusi secara daring atau melalui WhatsApp 
Group, e) kegiatan diskusi dilakukan beberapa kali, setiap anggota kelompok memberikan informasi dalam kelompok sampai mendapatkan solusi, dan f) kegiatan diskusi penutup, yaitu jika hasil diskusi telah mendapatkan solusi dari permasalahan. Kesimpulan hasil diskusi di kirim ke Google Classroom dalam bentuk file PDF.

Untuk mengetahui hasil belajar siswa, maka dilakukan kegiatan eksperimen sebanyak 3 kali dan 1 kali tes pada masing-masing kelas.
Diperoleh hasil tes nilai tertinggi adalah 92 dan nilai terendah adalah 60 dengan interval penilaian 1-100. Rata-rata skor hasil belajar siswa di kelas eksperimen pada tes pretests adalah 76,2 dan posttests adalah 87,7. Sedangkan rata-rata skor hasil belajar siswa di kelompok kontrol pada tes pretests adalah 74,4 dan posttests adalah 81,8 . Perbandingan ratarata skor kelas eksperimen dan kelas kontrol dilihat pada Tabel 1 .

Tabel 1.

Pretests dan Posttests Kelas Eksperimen dan Kelas Kontrol

\begin{tabular}{|c|c|c|c|c|c|c|c|}
\hline \multirow{2}{*}{ No } & \multirow{2}{*}{ Nama } & \multicolumn{2}{|c|}{ Kelompok Eksperimen } & \multirow{2}{*}{ No } & \multirow{2}{*}{ Nama } & \multicolumn{2}{|c|}{ Kelompok Kontrol } \\
\hline & & Pretests (T1E) & Posttests (T2E) & & & Pretests (T1C) & Posttests (T2C) \\
\hline 1 & A.K & 76 & 84 & 1 & A.R & 92 & 88 \\
\hline 2 & A.R & 80 & 84 & 2 & A.A & 84 & 88 \\
\hline 3 & A.L & 88 & 96 & 3 & A.S & 64 & 76 \\
\hline 4 & A.S & 72 & 76 & 4 & A.B & 80 & 84 \\
\hline 5 & C.K & 84 & 92 & 5 & B.S & 84 & 84 \\
\hline 6 & C.N & 92 & 96 & 6 & C.R & 88 & 92 \\
\hline 7 & C.P & 68 & 80 & 7 & D.R & 84 & 88 \\
\hline 8 & D.R & 92 & 96 & 8 & D.S & 64 & 76 \\
\hline 9 & D.S & 88 & 96 & 9 & E.P & 80 & 80 \\
\hline 10 & E.D & 72 & 76 & 10 & E.T & 76 & 80 \\
\hline 11 & E.S & 84 & 92 & 11 & E.G & 88 & 88 \\
\hline 12 & F.M & 92 & 96 & 12 & F.B & 60 & 72 \\
\hline 13 & F.D & 88 & 96 & 13 & F.K & 84 & 88 \\
\hline 14 & G.T & 68 & 92 & 14 & FM & 72 & 76 \\
\hline 15 & G.S & 80 & 84 & 15 & G.S & 60 & 76 \\
\hline 16 & I.L & 80 & 88 & 16 & G.M & 76 & 80 \\
\hline 17 & J.P & 92 & 96 & 17 & J.S & 92 & 96 \\
\hline 18 & J.M & 84 & 88 & 18 & J.R & 64 & 76 \\
\hline 19 & M.Y & 84 & 92 & 19 & J.E & 64 & 76 \\
\hline 20 & N.M & 88 & 92 & 20 & M.I & 80 & 80 \\
\hline 21 & N.S & 80 & 88 & 21 & M.A & 60 & 76 \\
\hline 22 & R.I & 68 & 76 & 22 & N.K & 72 & 80 \\
\hline 23 & R.S & 88 & 92 & 23 & N.D & 68 & 72 \\
\hline 24 & S.R & 72 & 80 & 24 & P.S & 68 & 84 \\
\hline 25 & T.F & 80 & 84 & 25 & R.W & 68 & 80 \\
\hline 26 & T.R & 76 & 84 & 26 & R.B & 72 & 80 \\
\hline 27 & V.S & 88 & 92 & 27 & S.T & 76 & 84 \\
\hline 28 & Y.S & 80 & 88 & 28 & S.N & 76 & 76 \\
\hline 29 & Z.S & 76 & 80 & 29 & S.K & 80 & 84 \\
\hline 30 & Z.M & 84 & 92 & 30 & W.Y & 88 & 96 \\
\hline \multicolumn{2}{|c|}{ Jumlah $\left(\sum\right)$} & 2.288 & 2.632 & \multicolumn{2}{|c|}{ Jumlah $\left(\sum\right)$} & 2.232 & 2.456 \\
\hline \multicolumn{2}{|c|}{ Rata-rata (X) } & 76,2 & 87,7 & \multicolumn{2}{|c|}{ Rata-rata (X) } & 74,4 & 81,8 \\
\hline
\end{tabular}

Sumber: Hasil penelitian, 2020.

Berdasarkan dari data pada Tabel 1, angka rata-rata yang dicapai dari kelompok eksperimen pretests (T1E) dan posttests (T2E) adalah 76,2 dan 87,7 dimana angka tersebut bervariasi mulai dari 68-92 untuk nilai pretests dan 76-96 untuk nilai posttests, sedangkan untuk siswa kelompok kontrol pada pretests (T1C) dan posttests (T2C) adalah 74,4 dan 81,8 dimana angka tersebut juga bervariasi mulai dari 60-92 untuk nilai pretests dan 72-96 untuk nilai posttests. Perbedaan hasil yang diperoleh dari siswa kelas eksperimen dan kelas kontrol diaplikasikan pada rumus. berikut:

Berdasarkan rumus diperoleh nilai

$$
=(\mathrm{T} 2 \mathrm{E}-\mathrm{T} 1 \mathrm{E})-(\mathrm{T} 2 \mathrm{C}-\mathrm{T} 1 \mathrm{C})
$$




$$
\begin{aligned}
& =(87,7-76,2)-(81,8-74,4) \\
& =(11,15)-(7,4) \\
& =4,1
\end{aligned}
$$

Berdasarkan hasil perhitungan diatas, kelas eksperimen mendapat nilai 11,15 sedangkan kelas kontrol mendapat nilai 7,4. Hal tersebut menunjukkan hasil belajar siswa meningkat akibat model pembelajaran berbasis masalah.

\section{PEMBAHASAN}

Berdasarkan hasil penelitian dan analisis data memberikan gambaran bahwa rata-rata skor hasil belajar siswa berdasarkan pembelajaran yang dilakukan dengan menggunakan model pembelajaran berbasis masalah pada kelas eksperimen lebih tinggi dibanding tanpa menggunakan model pembelajaran berbasis masalah pada kelas kontrol.

Hal tersebut menjelaskan terjadi peningkatan kemampuan siswa mencakup aspek kognitif, afektif dan psikomotor. Peningkatan aspek kognitif terlihat pada hasil belajar. Aspek afektif dan psikomotor dapat diidentifikasi ketika guru melalukan kunjungan kepada beberapa kelompok siswa dirumah siswa yang melakukan diskusi dalam pengerjaan tugas. Kegiatan diskusi mendorong siswa untuk dapat memecahkan masalah dari tugas untuk diselesaikan bersama secara kooperatif. Siswa mampu membuat argumentasi dan perumusan hipotesis-hipotesis dari permasalahan yang kemudian dibuat kesimpulan. Hal tersebut menjelaskan bahwa penerapan model pembelajaran berbasis masalah dapat meningkatkan hasil belajar siswa pada mata pelajaran Geografi.

\section{KESIMPULAN}

Penerapan model pembelajaran berbasis masalah dipadukan dengan metode pembelajaran daring efektif dan efisien untuk meningkatkan hasil belajar siswa. Penerapan model pembelajaran berbasis masalah dapat dipadukan dengan metode pembelajaran daring juga mampu meningkatkan keaktifan dan kreativitas siswa selama pembelajaran berlangsung. Peningkatan hasil belajar siswa dapat dilihat dari perbandingan hasil belajar kelas eksperimen dengan pretes 76,2 dan posttests 87,7 dan kelas kontrol dengan pretests 74,4 dan posttests 81,8 . Selain itu, dengan model pembelajaran ini mendorong siswa lebih aktif dan kreatif dalam mengatasi masalahmasalah yang dihadapi dalam pembelajaran.

\section{SARAN}

Guru sebagai tenaga pengajar di sekolah agar kiranya lebih kreatif dalam melakukan kegiatan pembelajaran terutama dalam pembelajaran daring menggunakan model pembelajaran berbasis masalah. Guru harus mampu memilih model pembelajaran untuk meningkatkan hasil belajar siswa yang sesuai kondisi dan keadaan yang tepat seperti pada masa pandemi serta mampu meningkatkan efektivitas pembelajaran.

\section{DAFTAR PUSTAKA}

Dimyati, dan Mudjiono. 1999. Belajar dan Pembelajaran. Rineka Cipta.

Pese, H., Lamba, H. A., \& Ali, M. 2012. Penerapan Model Pembelajaran Kooperatif Tipe Artikulasi Untuk Meningkatkan Hasil Belajar Fisika Siswa Pada Kelas Viiib SMP Negeri 2 Marawola. JPFT (Jurnal Pendidikan Fisika Tadulako Online), 1(1), 42-47.

Putri, A. R., \& Muzakki, M. A. 2019. Implemetasi Kahoot Sebagai Media Pembelajaran Berbasis Digital Game Based Learning Dalam Mengahadapi Era Revolusi Industri 4.0. Prosiding Seminar Nasional Universitas Muria Kudus, 1-7.

Rasyid. 2018. Penerapan Model Pembelajaran Berbasis Masalah Untuk Meningkatkan Hasil Belajar Geografi Materi Biosfer Serta Persebaran Flora dan Fauna Pada Siswa IPS 2 SMA Negeri 5 Bau-Bau. Jurnal Penelitian Pendidikan Geografi, 3(3), 350-364.

Rifani, I. 2013. Pengaruh Model Pembelajaran Learning Cycle dan Model Pembelajaran Search, Solve, Create, and Share Terhadap Pemahaman Konsep-Konsep Geografi. Jurnal Geografi Gea, 13(1).

Rosma. 2017. Upaya Meningkatkan Hasil Belajar Siswa dalam Mata Pelajaran IPA melalui Model Pembelajaran Artikulasi pada Siswa Kelas X IPA 3 SMA 1 Lembah Melintang. Jurnal Manajemen 
Pendidikan, 2(1), 221-230.

Rusman. 2011. Model-Model Pembelajaran: Mengembangkan Profesionalisme Guru. PT Raja Grafindo Persada.

Sumartini, T. S. 2015. Peningkatan kemampuan Penalaran Matematis Siswa Melalui Pembelajaran Berbasis Masalah. Mosharafa: Jurnal Pendidikan Matematika, 4(1), 1-10.

Wahyuni, S., Areva, D., dan Dahen, L. D. 2014. Proses Penetapan Kriteria Ketuntasan Minimal (KKM) pada Mata Pelajaran Ekonomi Kelas X di SMA Se-Kecamatan
Lubuk Kilangan Kota Padang. Jurnal Ipteks Terapan, 8(3), 105-111.

Widodo, I., Mukminan, M. 2018. Pengembangan E-Learning Mata Pelajaran Geografi untuk Meningkatkan Hasil Belajar Peserta Didik Kelas X SMA. Jurnal Inovasi Teknologi Pendidikan, $5(1), 12-25$.

Woa, K. M. 2018. Pengaruh Model Pembelajaran Problem Based Learning Terhadap Kemampuan Berpikir Kritis dan Memecahkan Masalah Geografi pada Siswa SMA. Universitas Negeri Malang. 